\title{
UPAYA MENINGKATKAN KETERAMPILAN MOTORIK HALUS MELALUI KEGIATAN FINGER PAINTING PADA ANAK USIA DINI DI KOBER ROFA SUKADANA LAMPUNG TIMUR
}

\author{
Anita Oktaviana, Basri, Uswatun Hasanah \\ IAIN Metro Lampung \\ E-mail: anitaokta45@gmail.com, basrin8@gmail.com, \\ uswahdeini@gmail.com
}

\begin{abstract}
The purpose of this study was to improve fine motor skills through Finger painting activities at KOBER Rofa Sukadana, East Lampung. This type of research is Classroom Action Research which is carried out through 2 cycles. To determine the level of child development, researchers used an observation sheet. Based on the results of research that has been conducted, it was found that Finger painting activities can improve the fine motor skills of children in KOBER Rofa Sukadana, East Lampung. These results can be seen from the results of the second cycle assessment which shows that fine motor skills have reached the expected development criteria, namely $\mathrm{BSH}$ (Developing according to expectations). The same results can be seen when the Finger painting activity process takes place, children are able to coordinate their eyes and hands. So it can be concluded that the children are able to use their hands and fingers to paint well and their fingers appear flexible during painting activities.
\end{abstract}

Keywords : fine motor skill; Finger painting

\section{Abstrak}

Tujuan dari penelitian ini adalah untuk meningkatkan keterampilan motorik halus melalui kegiatan Finger painting di KOBER Rofa Sukadana Lampung Timur. Jenis penelitian ini adalah Penelitian Tindakan Kelas yang dilaksanakan melalui 2 siklus. Untuk mengetahui tingkat perkembangan anak peneliti menggunakan lembar observasi. Berdasarkan hasil penelitian yang telah 
dilakukan, ditemukan bahwa kegiatan Finger painting dapat meningkatkan keterampilan motorik halus anak di KOBER Rofa Sukadana Lampung Timur. Hasil tersebut dapat dilihat dari hasil penilaian siklus II yang menunjukan bahwa keterampilan motorik halus sudah mencapai kriteria perkembangan yang diharapkan yaitu BSH (Berkembang Sesuai Harapan). Hasil yang sama dapat diilihat saat proses kegiatan Finger painting berlangsung, anak sudah dapat mengkoordinasi mata dan tangannya. Sehingga dapat disimpulkan bahwa anak-anak sudah dapat menggunakan tangan dan jari-jarinya untuk melukis dengan baik serta jari-jari anak nampak lentur pada saat kegiatan melukis.

Kata Kunci : motorik halus; Finger painting

\section{Pendahuluan}

Anak pada usia dini belum mampu berpikir abstrak. Mereka lebih banyak meniru dan menyerap lewat pancaindranya. Pada umur tersebut mereka tertarik kepada guru yang ramah, penyayang, dan suka memperhatikannya, Kadang mereka lebih mengagumi dan menyayangi gurunya daripada orangtuanya, terutama mereka yang kurang mendapat kasih sayang dari orangtuanya (Ichsan Dacholfany \& Uswatun Hasanah, 2018:5)

Aspek perkembangan anak khususnya perkembangan fisik motorik sangat penting untuk melatih koordinasi gerakan yang melibatkan bagian-bagian tubuh. Aspek perkembangan motorik dibedakan menjadi dua yaitu motorik kasar dan motorik halus. Secara umum, aspek motorik kasar akan berkembang lebih dahulu dari pada aspek motorik halus. Oleh karena itu, diperlukan stimulasi agar aspek motorik kasar dan motorik halus dapat berkembang secara seimbang sehingga anak tidak hanya mampu berlari, melompat, menendang tetapi keterampilan motorik halusnya seperti menulis, melukis, menggunting, meronce, menjahit dan menggambar juga dapat berkembang. 
Finger painting atau melukis dengan jari adalah teknik melukis dengan jari tangan secara langsung tanpa menggunakan bantuan alat. Jenis kegiatan ini dilakukan dengan cara mengoleskan adonan warna (bubur warna) menggunakan jari tangan di atas bidang gambar, batasan jari yang digunakan adalah semua jari tangan, telapak tangan, sampai pergelangan tangan (Anies Listyowati, 2010:2)

Berdasarkan hasil survey dan wawancara pada tanggal 17 Juli 2019, Perkembangan motorik halus anak di KOBER Rofa Sukadana usia 3-4 tahun masih kurang berkembang terutama dalam kegiatan menggerakan jari tangan dan kemampuan untuk menggengam dan memegang benda. Hal ini terjadi karena dalam pembelajaran Motorik halus anak hanya diberi kegiatan mewarnai gambar bebas menggunakan krayon dan kegitan menjplak jari tangan menggunakan pensil. Berdasarkan hasil observasi juga terdapat banyak anak di KOBER Rofa Sukadana yang perkembangan motorik halusnya belum berkembang dengan baik. Hal ini terlihat pada pencapaian indikator, dari jumlah 17 anak, yang belum berkembang ada 9 anak, yang mulai berkembang ada 4 anak, dan yang berkembang sesuai harapan ada 4 anak. Beberapa kegiatan yang dapat mengembangkan kemampuan motorik halus anak salah satunya adalah kegiatan Finger painting.

Keterampilan motorik halus merupakan aktivitas yang melibatkan penggunaan gerakan otot halus seperti kegiatan menggambar, menulis, mengikat tali sepatu, dan Finger painting atau melukis menggunakan jari. Keterampilan motorik halus berkembang lebih lambat pada anak-anak prasekolah (Sudarwan Danim, 2010:47).

Kemampuan motorik merepresentasikan keinginan anak.misalnya, ketika anak melihat mainan dngan beraneka 
ragam, anak mempersepsikan dalam otaknya bahwa dia ingin memainkannya. Persepsi tersebut memotivasi anak untuk melakukan sesuatu, yaitu bergerak untuk mengambilnya. Akibat gerakan tersebut, anak berhasil mendapatkan apa yang diinginkannya, yaitu mengambil mainan yang menarik baginya. Teori tersebut menjelaskan bahwa ketika anak dimotivsi untuk melakukan sesuatu, mereka dapat menciptakan kemampuan motorik yang baru, kemampuan baru tersebut merupakan hasil dari banyak faktor yaitu perkembangan sistem syaraf, kemampuan fisik yang memungkinkannya untuk bergerak, keinginan anak yang memotivasinya untuk bergerak, dan lingkungan yang mendukung memperoleh kemampuan motorik(Ahmad Rudiyanto, 2016:17-18)

Belajar keterampilan motorik halus menurut Muhibbin Syah (2010:61-62) dianggap telah terjadi dalam diri seorang anak apabila anak telah memperoleh kemampuan dan keterampilan yang melibatkan penggunaan tangan seperti menggambar, menulis, melipat, meremas dan menggunting dengan benar. Untuk belajar memperoleh kemampuan keterampilan tersebut anak tidak hanya cukup dengan latihan dan praktik, tetapi juga memerlukan kegiatan belajar berdasarkan pengamatan. Aktivitas latihan perlu dilaksanakan dalam bentuk praktik yang berulangulang oleh siswa dengan pengamatan guru. Sehingga siswa dapat memahami bagian yang keliru dan dapat segera melakukan melakukan perbaikan. Akan tetapi, dalam praktik hendaknya dilibatkan pengetahuan ranah akal anak.

Disaat usia 6 tahun, perkembangan motorik halus anak lebih sempurna dan terkoordinasi dengan baik, seiring bertambahnya berat dan kekuatan badan anak. Mereka terlihat sudah mampu mengontrol dan mengkoordinasikan gerakan anggota tubuhnya 
seperti tangan. Otot-otot tangan sudah mulai kuat sehingga dapat beraktivitas dengan baik(Desmita, 2009:79-80)

Meskipun anak mungkin dapat melakukan aktivitas motorik kasar dengan baik, dalam melakukan aktivitas motorik halus belum tentu demikian. Strategi pengembangan motorik halus mencakup (a) Menggunting, Menggunting hendaknya dimulai dari menggunting lurus dekat tepi kertas, baru kemudian menggunting lurus ditengah kertas, (b) Memotong, Memotong hendaknya anak diajarkan memotong bentuk-bentuk yang mudah misalnya memotong bentuk-bentuk geometri seperti bujur sangkar, empat persegi panjang, segitiga dan sebagainya, (c) Melipat kertas, Melipat kertas anak diajarkan untuk membentuk burung, perahu kertas, kipas, dan lain sebagainya(Mulyono Abdurrahman, 2012:124)

Kegiatan Finger painting dapat mengasah imajinasi, kreativitas, serta dapat mengembangkan kecerdasan kognitif anak seperti mengenal nama-nama jari dan berbagai macam bentuk dan warna.Berikut ini cara menjiplak bentuk katak menggunakan jari tangan yaitu sebagai berikut:Rapatkan keempat jari tangan dan letakkan pada posisi terbuka dan menyamping, Tempelkan pada kertas yang sudah disediakan, Tebalkan menggunakan pensil agar membentuk jiplakan berbentuk katak, Tambahkan garis bantu untuk membentuk mulut, mata, dan kaki, Lalu warnai mulut, mata, dan kaki tersebut sesuai dengan warna yang sebelumnya(Yumnas Muklis, 2016:9)

Selain kegiatan menggambar dan melukis, kegiatan seni rupa yang juga sangat disukai oleh anak-anak adalah kegiatan melukis dengan jari tangan atau biasa dikenal dengan namaFinger painting. Dalam kegiatan Finger painting anak harus melukis dengan jari-jarinya dan tidak diperbolehkan menggunakan alat 
bantu seperti yang dilakukan dalam kegiatan menggambar atau melukis biasa yang pada umumnya menggunakan pensil, crayon, kuas, dan sebagainya. Hal ini bukan tanpa sebab, akan tetapi memiliki tujuan yang baik untuk melatih keterampilan motorik halus anak. Berikut ini adalah tujuan dari Finger painting yaitu:

a. Dapat melatih motorik halus pada anak yang melibatkan gerak otot-otot kecil dan kematangan syaraf.

b. Dapat mengenal konsep warna primer (merah, kuning, biru). Dari warna-warna yang terang seseorang dapat mengetahui kondisi emosi anak, kegembiraan dan kondisikondisi emosi mereka.

c. Mengenalkan konsep pencampuran warna primer. Sehingga menjadi warna yang sekunder dan tersier.

d. Mengenalkan estetika keindahan warna dengan menggambar karya-karya kreatif.

e. Melatih keterampilan motorik halus, imajinasi, dan kreativitas.

f. Meningkatkan kemampuan berpikir dan berbuat kreatif. (Novi Mulyani, 2017:68)

\section{Metode Penelitian}

Adapun metode peneleitian yang dilakukan dalam penelitian ini adalah Penelitian Tindakan Kelas (PTK) ini dilakukan pada anak-anak di KOBER Rofa Sukadana Lampung Timur pada tahun ajaran 2019/2020. Subjek dalam penelitian ini adalah anak-anak di KOBER Rofa Sukadana yang terdiri dari 17 anak, yakni 10 anak perempuan dan 7 anak laki-laki pada tahun ajaran 2019/2020. Adapun Pelaksanaan dalam penelitian tindakan kelas ini terdiri dari 2 siklus untuk melihat peningkatan hasil belajar dan aktivitas anak dalam mengikuti pembelajaran Finger painting. Masing- 
masing siklus terdiri dari 3 kali pertemuan, dan setiap siklusnya terdiri dari empat tahapan kegiatan, yaitu: tahap perencanaan, tahap pelaksanaan, tahap pengamatan atau observasi dan tahap refleksi.

\section{Hasil dan Pembahasan}

Finger painting atau sering di sebut juga dengan kegiatan melukis menggunakan jari, Finger painting merupakan salah satu kegiatan teknik melukis tanpa alat bantu apapun dengan cara mengoleskan cat pada kertas basah menggunakan jari jemari yang dapat dilakukan anak untuk menuangkan imajinasinya melalui lukisan yang dibuat dengan jari jemari, dalam kegiatan ini dapat melatih motorik halus dan kreativitas yang dimiliki oleh anak. Melalui kegiatan Finger painting anak dapat mengekspresikan diri dalam berkreativitas seni. Selain itu, kegiatan Finger painting dapat melatih anak untuk melenturkan jari jemari dan mengontrol koordinasi mata dan tangan(Nina Astria dan Made Sulastri, 2015:3)

Pembelajaran Finger painting menurut Galih Efendi dan Agus Sudarmawan (2017:4-8) dilakukan secara terbimbing oleh guru, sehingga media dapat secara maksimal digunakan, yakni melibatkan semua bagian jari dan telapak tangan untuk melatih motorik halus anak. Pelaksanaan pembelajaran dilakukan dengan sistem area, dengan menerapkan metode pembelajaran belajar sambil bermain. Pembelajaran Finger painting dilaksanakan dengan menyiapkan media warna, dan keperluan pembelajaran di dalam kelas, seperti menata meja belajar anak, melapisi menggunakan taplak plastik atau koran bekas, serta memasangkan kain celemek pada baju anak agar tidak kotor. Selanjutnya guru menunjukan contoh karya jadi, serta 
mendemonstrasikan cara penggunaan media warna, kemudian guru menyuruh anak untuk melukis. Setelah selesai melukis, anak-anak disuruh untuk mencuci tangan, dan karya yang telah selesai dibuat oleh anak-anak dikumpulkan untuk di evaluasi. Langkah-langkah pelaksanaan pembelajaran Finger painting adalah sebagai berikut:

a. Pada setiap kelas guru mempersiapkan segala keperluan pembelajaran baik dari segi administrasi, maupun media pembelajaran berupa adonan warna.

b. Setelah media siap, pembelajaran Finger painting diawali dengan penyiapan segala keperluan pembelajaran di dalam kelas, seperti menata meja belajar siswa, melapisi menggunakan taplak plastik atau koran bekas, serta memasangkan kain celemek pada setiap baju anak yang mengikuti kegiatan lukis jari atau Finger painting.

c. Selanjutnya guru menunjukan contoh karya jadi, serta mengenalkan dan mendemonstrasikan cara penggunaan media warna di depan kelas, cara yang guru contohkan adalah menggunakan seluruh bagian jari tangannya untuk mewarnai media kertas.

d. Setelah dicontohkan cara kerjanya, kemudian guru menyuruh anak untuk melakukan kegiatan Finger painting pada kelompok pertama area seni, kegiatan ini dibimbing dan didampingi guru.

e. Setelah selesai melakukan kegiatan melukis, anak-anak kelompok pertama disuruh untuk mencuci tangan, kemudian berganti giliran dengan kelompok lain, karya yang telah selesai dibuat anak-anak dikumpulkan guru untuk diberi identitas serta dievaluasi.

f. Evaluasi pada kegiatan lukis jari/Finger painting ini dilakukan dengan aspek penilaian yaitu : melukis sesuai contoh yang 
diberikan guru, kerapian bentuk lukisan, mengoleskan adonan kelukisan secara merata, dan mengoleskan adonan tidak keluar dari pola.melalui proses kerja dan hasil yang anak buat, penilaian menggunakan 4 kriteria yakni belum berkembang (BB) dengan nilai bintang 1 , mulai berkembang (MB) dengan nilai bintang 2, berkembang sesuai harapan (BSH) dengan nilai bintang 3, serta berkembang sangat baik (BSB) dengan nilai bintang 4 .

Dari hasil penelitian siklus I dan siklus II menunjukkan adanya peningkatan keterampilan motorik halus anak di yang ditandai dengan hasil penilaian motorik anak dengan indikator berkembang sesuai harapan. Berikut ini adalah hasil akhir keterampilan motorik halus anak melalui kegiatan Finger painting pada prasiklus, siklus I, dan siklus II yang digambarkan melalui diagram batang dibawah ini:

Gambar 1

Perbandingan Hasil Motorik Halus Pada Prasiklus, Siklus I, dan Siklus II

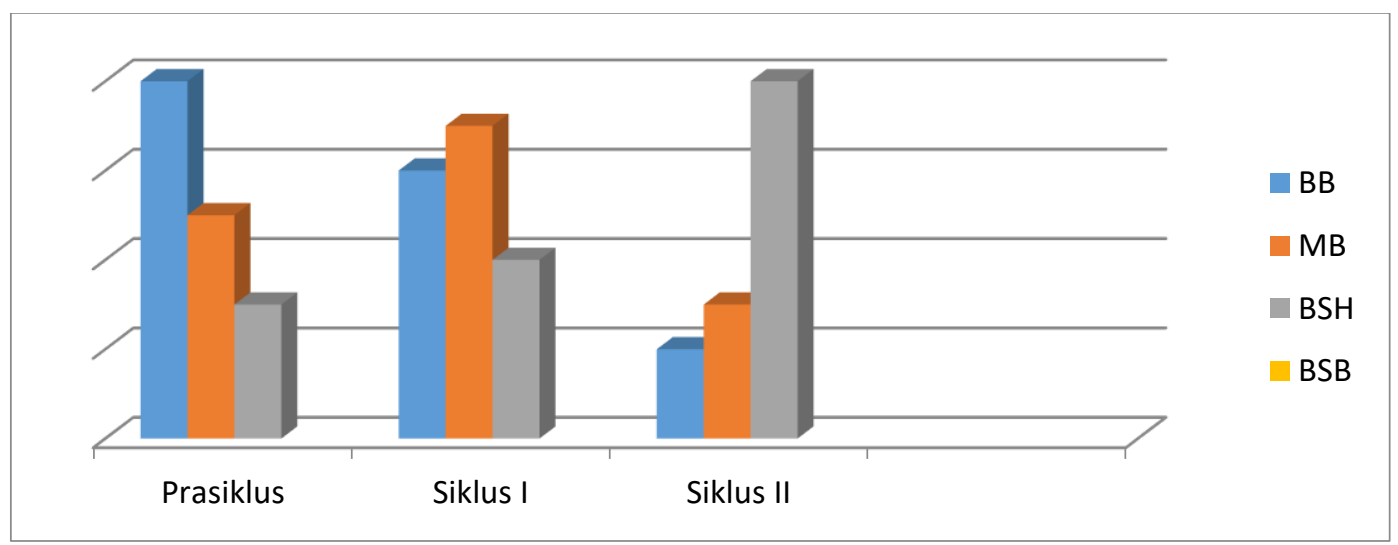

Berdasarkan gambar 1 dapat kita amati adanya peningkatan kemampuan motorik halus anak dalam kegiatan Finger painting. Hal itu menunjukkan adanya dampak positif dari kegiatan Finger 
painting. Dari hasil penelitian juga terdapat beberapa perubahan yang timbul pada saat kegiatan berlangsung antara lain:

1. Dalam kegiatan Finger painting dapat menimbulkan semangat baru bagi anak dalam berkarya seni.

2. Membantu anak dalam mengembangkan motorik halusnya, seperti mengkoordinasikan gerakan jari tangan dan mata. Perkembangan ini dilihat dari kegiatan anak dalam melaksanakan kegiatan melukis jari.

Dengan demikian berdasarkan hasil penelitian tindakan dan observasi yang telah dilakukan dapat disimpulkan bahwa Finger painting dapat meningkatkan keterampilan motorik halus anak di KOBER Rofa Sukadana Lampung Timur pada tahun ajaran 2019/2020.

\section{Kesimpulan}

Berdasarkan hasil penelitian dan analisis data yang telah dilakukan, dapat disimpulkan bahwa kegiatan finger painting dapat meningkatkan keterampilan motorik halus di KOBER Rofa Sukadana Lampung Timur.

\section{Daftar Pustaka}

Abdurrahman, Mulyono. (2012). Anak Berkesulitan Belajar. Jakarta: Rineka Cipta.

Danim, Sudarwan. (2010). Perkembangan Peserta Didik. Bandung: Alfabeta.

Desmita. (2009). Psikologi Perkembangan Peserta Didik. Bandung: PT Remaja Rosdakarya.

Galih Efendi dan Agus Sudarmawan, (2017). Pelaksanaan Paembelajaran Lukis Jari atau Finger Painting Kelompok $B$ di TK Negeri Pembina Singaraja, Jurnal Pendidikan Anak Usia Dini 1, no. 6. 
Kementrian Pendidikan dan Kebudayaan, Direktorat Jendral Pendidikan Anak Usia Dini dan Pendidikan Masyarakat. (2015). Pedoman Penilaian Pembelajaran Anak Usia Dini, Jakarta: Direktorat Pembinaan Pendidikan Anak Usia Dini.

Listyowati, Anies. (2010). Finger Painting. Jakarta: Erlangga.

LN, Syamsu Yusuf. (2013). Perkembangan Peserta Didik. Jakarta: PT Raja Grafindo Persada.

M. Ihsan Dacholfany dan Uswatun Hasanah. (2018) Pendidikan Anak Usia Dini Menurut Konsep Islam. Jakarta: Amzah.

Muklis, Yunnas. (2016). Kreasi Seru Jari Tangan. Jakarta: Erlangga.

Mulyani, Novi. (2017). Pengembangan Seni Anak Usia Dini. Bandung: PT Remaja Rosdakarya.

Nina Astria dan Made Sulastri. (2015). Penerapan Metode Bermain Melalui Kegiatan Finger Painting Untuk Meningkatkan Kemampuan Motork Halus," Jurnal PG PAUD 3, no. 1.

Rudiyanto, Ahmad. (2016). Perkembangan Motorik Kasar dan Motorik Halus Anak Usia Dini. Lampung: Darussalam Press.

Syah, Muhibbin. (2010). Psikologi Pendidikan. Bandung: PT Remaja Rosdakarya.

Yani Mulyani dan Gracinia Juliska. (2007). Kemampuan Fisik, Seni, dan Manajemen Diri. Jakarta: PT Elex Media Komputindo. 